\title{
Near-Field Immunity Test Method for Fast Radiated Immunity Test Debugging of Automotive Electronics
}

\author{
Jawad Yousaf ${ }^{1,+}{ }^{1}$, Doojin Lee ${ }^{1,2,+}$, JunHee Han ${ }^{1,+}{ }^{,}$, Hosang Lee ${ }^{1}$, Muhammad Faisal ${ }^{1}$, \\ Jeongeun $\operatorname{Kim}^{1}$ and Wansoo $\mathrm{Nah}^{1, *}$ \\ 1 Department of Electrical and Computer Engineering, Sungkyunkwan University, Suwon 16419, Korea \\ 2 Electronics Engineering Design Team 1, MANDO Corp., Seongnam 463400, Korea \\ * Correspondence: wsnah@skku.edu; Tel.: +82-31-290-7136 \\ + These authors contributed equal to this work.
}

Received: 21 June 2019; Accepted: 13 July 2019; Published: 16 July 2019

\begin{abstract}
This study presents a near-field immunity test (NFIT) method for the fast debugging of radiated susceptibility of industrial devices. The proposed approach is based on the development of an NFIT setup which comprises of developed near-field electric and magnetic field probes and device under test (DUT). The developed small-size and handy near-field testing probes inject the high electric (up to $1000 \mathrm{~V} / \mathrm{m}$ ) and magnetic (up to $2.4 \mathrm{~A} / \mathrm{m}$ ) fields on the DUT in the radar pulse ranges (1.2 to $1.4 \mathrm{GHz}$ and 2.7 to $3.1 \mathrm{GHz}$ ) with the lower fed input power (up to $15 \mathrm{~W}$ ) from the power amplifier in the developed NFIT setup. The proof of concept is validated with the successful near-field immunity debugging of an electric power steering (EPS) device used in the automotive industry with the developed NFIT setup. The radiated susceptibility debugging test results of developed NFIT method and conventional method of ISO 11452-2 test setup turned out to be close to each other for the tested DUT in immunity performance. The proposed procedure has advantages of industry usefulness with fast, handy, and cost-effective radiated immunity debugging of the DUT without the requirement of large antenna, high-power amplifiers, optical DUT connecting harness, and an anechoic chamber as needed in ISO 11452-2 standard setup for the debugging analysis.
\end{abstract}

Keywords: radiated immunity (RI) test; near-field immunity test (NFIT); ISO 11452-2; automotive; radar pulse range; L-probe fed circular patch antenna; $\mathrm{H}$-field probe

\section{Introduction}

Modern technologies have revolutionized the manufacturing of autonomous and non-automated road vehicles. The performance of both driverless and human-controlled vehicles is dependent on the functionality of automotive electronics that control the wide range of car operations. The number of electronic devices and their integration complexities are increasing, especially in self-driving cars due to the Internet of Things (IoT) paradigm [1,2]. Because of the limited available space in cars, electronic devices in an automobile are installed in close vicinity which could generate electromagnetic (EM) interference problems among the devices and might result in malfunction of vehicle operation $[1,3]$. Besides the highly integrated "on-vehicle" EM sources such as antennas used for cellular communication, global positioning system (GPS) systems, navigation system, vehicle tracking, WiFi, dedicated short-range communications (DSRC), IoT connectivity, and automotive radars, etc., "off-vehicle" man-made or natural EM sources could also have an adverse impact on vehicle system performance $[1,3,4]$.

An example of a man-made EM source, particularly important for autonomous automobiles, is the pulse-modulated radar pulses that are used by military installations and commercial airport surveillance systems for the tracking of the aircraft [4-6]. These high-intensity (up to $600 \mathrm{~V} / \mathrm{m}$ ) radar 
pulses are generated by the Air Traffic Control (ATC) radars in the two frequency bands of $1.2-1.4 \mathrm{GHz}$ and 2.7-3.1 GHz, respectively $[4,6,7]$. The possible detection of these high-intensity waves by the vehicle system could impact on its performance with the disturbance in automotive electronics $[1,4,7,8]$.

For electromagnetic compatibility (EMC) compliance of vehicle electronics to such high-intensity EM wave disturbances, automotive vendors such as General Motors Worldwide (GMW) and Ford have defined pulsed radar radiated immunity (RI) qualification testing requirements in both aforementioned L- and S-band frequency ranges [9,10]. The maximum defined immunity level is $600 \mathrm{~V} / \mathrm{m}$ by the car-makers as illustrated in Table 1 and the RI qualification testing of the electrical/electronic components and subsystems of automotive vehicles is performed as per the international organization for standardization (ISO) 11452-2 standard test setup requirements [11].

Table 1. Radiated immunity test levels defined by the automotive vendors.

\begin{tabular}{ccccc}
\hline Vendor & Reference Standard & Frequency (GHz) & \multicolumn{2}{c}{ Field Level (V/m) } \\
\hline GMW & GMW 3097 [9] & $1.2-1.4$ & N/A & 600 \\
\hline \multirow{2}{*}{ Ford } & \multirow{2}{*}{ FMC 1278 [10] } & $1.2-1.4$ & \multirow{2}{*}{300} & 600 \\
\hline
\end{tabular}

ISO 11452-2 specifies an absorber-lined shielded enclosure (ALSE)-based test setup for the RI testing of road vehicles electronics. Figure 1 shows the far-field radiated susceptibility test setup of ISO 11452-2 [11]. In this setup, the distance between the DUT and the transmit antenna is $1 \mathrm{~m}$; therefore, the method is also referred to as ' $1 \mathrm{~m}$ method'. The test setup of [11] requires a very high-power amplifier in the range of $500 \mathrm{~W}$ to $1000 \mathrm{~W}$ (depending on the efficiency of chamber test setup) to produce up to $600 \mathrm{~V} / \mathrm{m}$ or higher level of incident EM waves for qualification testing in radar pulsed ranges [7]. Besides this requirement, in case of qualification test failure, it is difficult to examine the working of the automotive electronics (i.e., device under test (DUT)) with the attached harness and test equipment such as an oscilloscope and DUT monitoring tools etc., in the ALSE setup of ISO 11452-2 for the potential root-cause analysis due to the locality of the monitoring systems and DUT harness in the high EM field region. Also, in [11] setup, the phase center of the transmit antenna must focus on the center of DUT at or above $1 \mathrm{GHz}$ as illustrated in Figure 1 which makes it difficult to expose the both DUT and its harness at the same time within a flat field uniformity (FU) region. It makes the debugging process of root-cause identification quite difficult and expensive as the repetitive RI testing in [11] setup must be performed for any possible modification in the DUT.

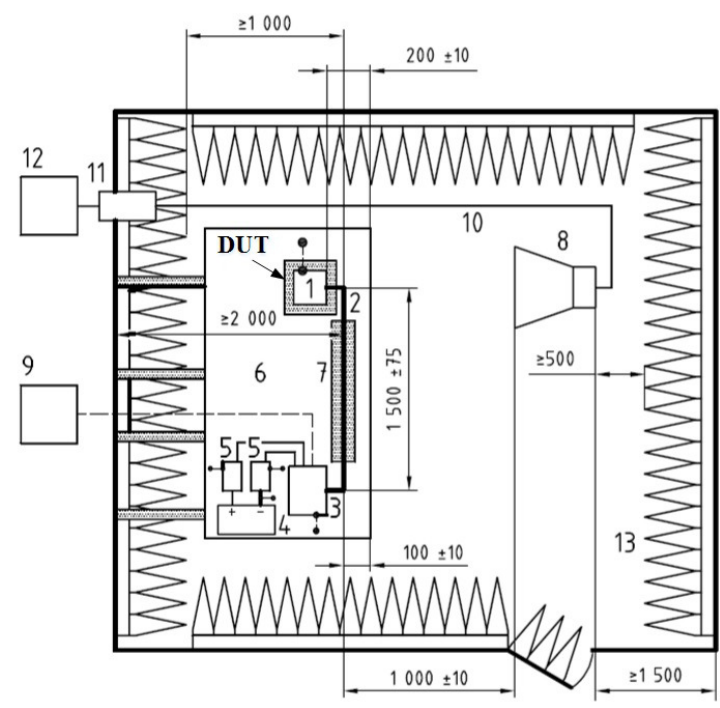

1 DUT (grounded locally if required in test plan)

2 Test harness

3 Load simulator (placement and ground)

4 Power supply (location optional)

5 Artificial network (AN)

6 Ground plane (bonded to shielded enclosure)

7 Low relative permittivity support

8 Horn antenna

9 Stimulation and monitoring system

10 High quality double-shielded coaxial cable ( $50 \Omega$ )

11 Bulkhead connector

$12 \mathrm{RF}$ signal generator and amplifier

$13 \mathrm{RF}$ absorber material

Figure 1. ISO 11452-2 far-field radiated immunity test setup for frequencies above $1 \mathrm{GHz}$ [11]. 
This study proposes a simple laboratory-based method for the near-field immunity test (NFIT) of the DUT for fast debugging of potential cause of error in DUT operation. Figure 2 shows the proposed NFIT setup (details in Section 2). The DUT is placed on a metallic sheet plane and is exposed to the high-intensity EM waves from the designed electric and magnetic field probes in the near field. Since the DUT is located approximately $50 \mathrm{~mm}(d)$ away from the designed field probes, the power amplifier consumes little power (up to $15 \mathrm{~W}$ ) to produce the same level of the electric field (i.e., $\geq 600 \mathrm{~V} / \mathrm{m}$ ) as required in ISO 11452-2, which makes the whole system small, handy, and cost-effective. Two electric field probes (L-probe-fed circular patch antennas) and one magnetic field probe (printed square loop antenna) covering the frequency bands of the two radar pulses $(1.2-1.4 \mathrm{GHz}$ and $2.7-3.1 \mathrm{GHz}$ ) and producing the required field levels with a minimum input power of around $15 \mathrm{~W}$ are designed and fabricated for the proposed test setup. The proposed immunity test system was used to test the electromagnetic immunity of an actual automotive electronic equipment (an electric power steering (EPS) device used in automotive vehicles), and proved to be valid to find the low immunity of DUT. It demonstrates that the proposed NFIT setup could be used for the fast debugging of the DUT for root-cause analysis by exposing both DUT and its harness at the same time. It was also found that performance signals of the DUT can be checked using monitoring equipment (e.g., oscilloscope etc.) during the test in the proposed NFIT method, which makes the debugging process quite easy. It is pertinent to mention here that the proposed NFIT method is not the replica or equivalent to the far-field ALSE setup of ISO 11452-2 and cannot be used for the qualification testing as specified by $[9,10]$. We propose a new way for the fast debugging of the complete DUT including harness to find the root cause and applying the possible remedy to rectify it quickly. After resolving the cause of failure, final compliance qualification testing of the DUT must be performed as per [11] requirements to meet the vendor's requirements $[9,10]$ as needed.

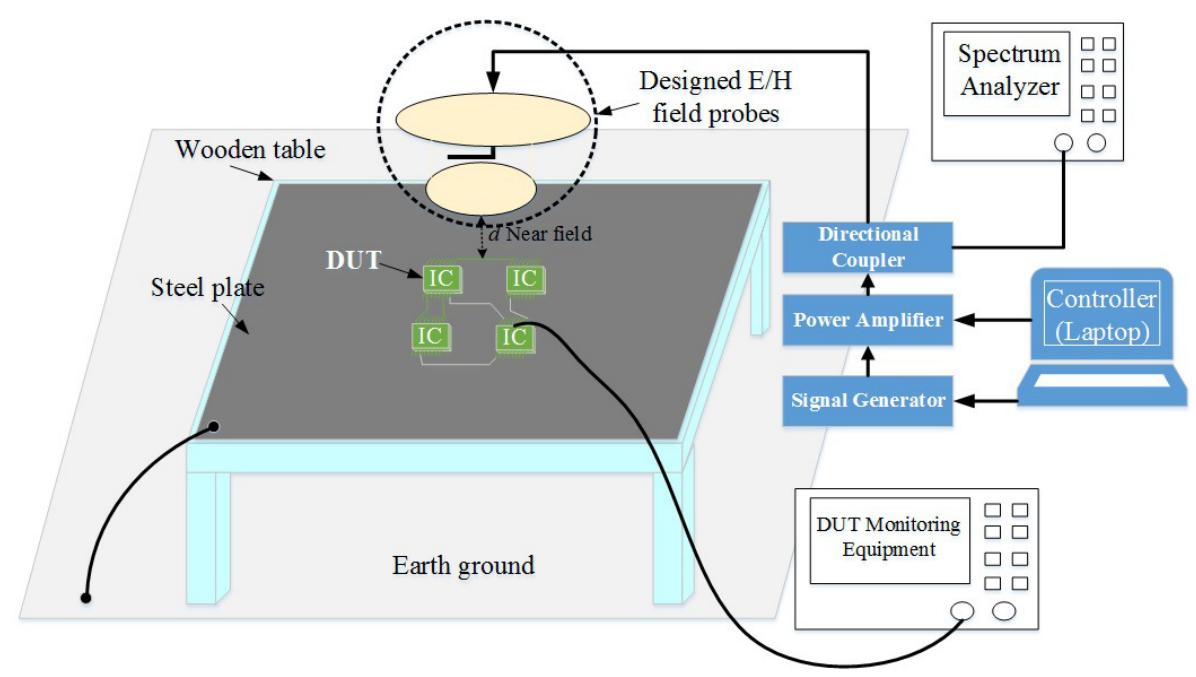

Figure 2. Proposed near-field immunity test (NFIT) setup for fast radiated immunity debugging of DUT.

The major contributions of this work are:

- Proposing a laboratory test setup for the fast and handy radiated near-field immunity test (NFIT) measurements of the automotive DUT in the radar pulse range

- Development and fabrication of the new electric and magnetic field probes for the injection of the desired high-intensity E- and H-field levels ( $\geq 600 \mathrm{~V} / \mathrm{m}$ and $\geq 1.59 \mathrm{~A} / \mathrm{m}$ respectively) on the DUT in the radar pulse range in the proposed NFIT setup.

- Validation of the proposed NFIT setup with the real-time RI measurements of an automotive industry electronic DUT (case study analysis) in both far-field test setup and proposed setup 
(see Figure 2) for the reproduction of the disturbance in the DUT functionality in both test setups as illustrated in Figure 3 (details in Section 2).

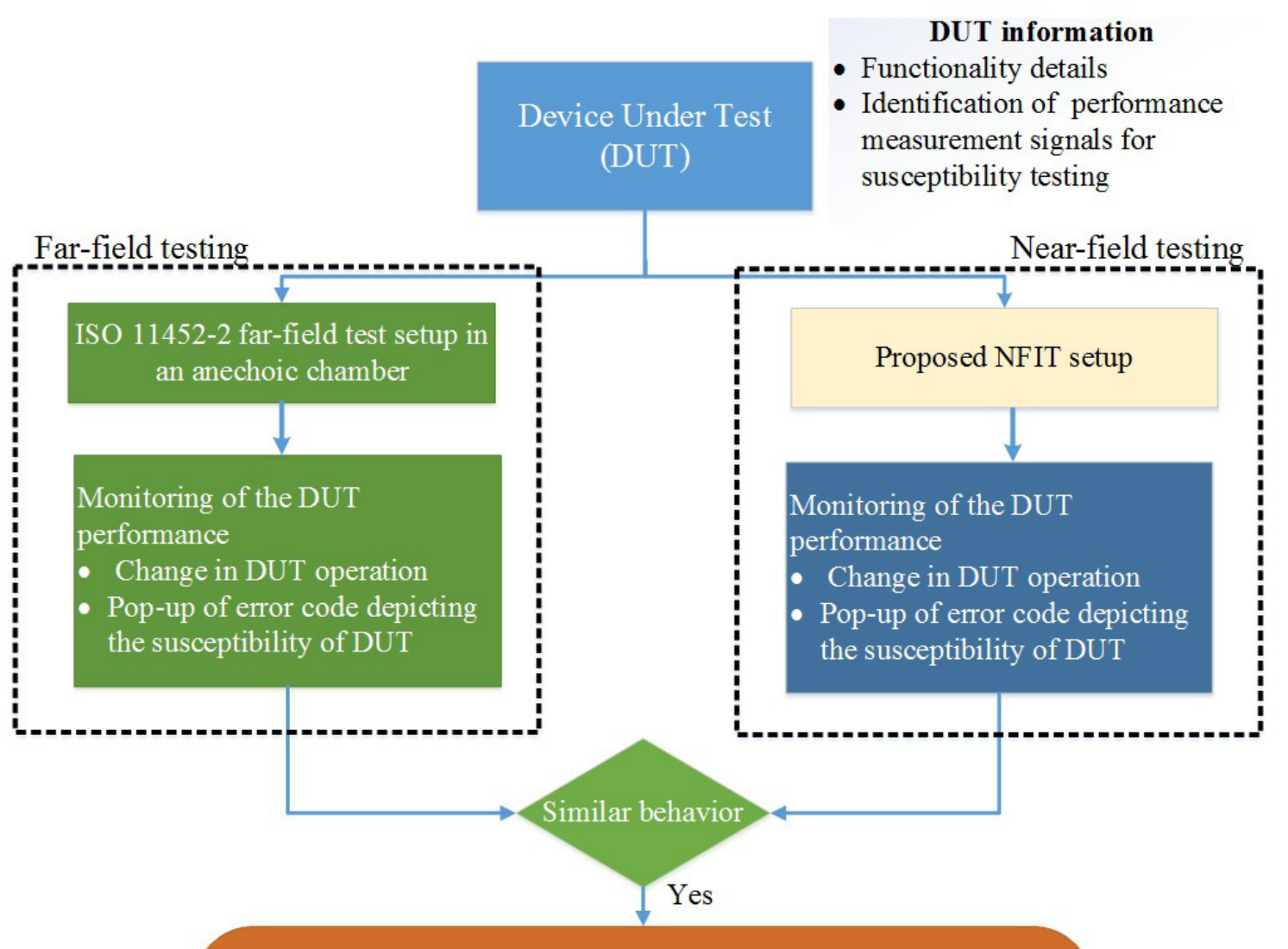

Proposed NFIT setup for fast radiated immunity debugging of DUT

Figure 3. Flow chart used for the verification of the proposed NFIT setup.

The remaining of the paper is organized as follows: Section 2 discusses the details of the proposed NFIT method. The design, simulation, and fabrication details of the designed near-field electric and magnetic field probes are described in Section 3. Section 4 presents the validation results of the proposed method with a case study analysis results of an actual automotive industry electronic equipment. Lastly, Section 5 draws some conclusion of the proposed study.

\section{Developed Near-Field Immunity Test (NFIT) Setup}

The schematic of the suggested NFIT method is depicted in Figure 2. The DUT is placed on a steel ground plane which is connected to the reference earth ground as per the ISO 11452-2 standard requirements. The designed and fabricated $\mathrm{E}$ - and $\mathrm{H}$-field probes are placed above the DUT at a distance ' $d$ ' as shown in Figure 2. We used the $d=50 \mathrm{~mm}$ in our setup and this distance was estimated based on the trial-and-error simulation approach to get the uniform electric and magnetic field injection on the DUT from the designed probes. The probes are fed from the signal generator through a power amplifier and a directional coupler. The directional coupler is used in experimental setup to monitor the actual feeding power to the probes.

Besides the simple setup, the good thing in the proposed method is to monitor the real DUT performance signals during the test as needed for root-cause analysis, because the injected electric and magnetic fields from the designed probes are local and are not affecting the monitoring equipment (e.g., oscilloscope) and attached harness as compared to Figure 1 setup [11]. In [11] setup, optical 
monitoring tools and harness could be used, at the cost of additional expenses, to avoid the influence of the injecting EM waves on DUT and interconnecting harness for the actual estimation of the reason of failure (root-cause determination) of the DUT for the exposed EM waves. On the contrary, we do not need any such expensive optical monitoring equipment in the proposed NFIT setup due to the locality of the generated EM waves which only affects the intended DUT region.

Although in the far-field test setup of [11] the DUT is exposed to EM waves, the actual qualification testing of the DUT is performed only for the specified E-field levels $(300 \mathrm{~V} / \mathrm{m}$ or $600 \mathrm{~V} / \mathrm{m})$ in the standards $[9,10]$. However, in the proposed NFIT method, due to the placement of the DUT in the vicinity of the field probes, the debugging analysis is conducted for both electric $(\mathrm{E})$ and magnetic $(\mathrm{H})$ field sources in the near field. The direction of propagation of the injected fields is same in both far-field and proposed NFIT setup. The far-field testing in ISO 11452-2 is performed for both horizontal and vertical polarizations for qualification testing. Also, the same approach could be used in the proposed NFIT method for effective debugging.

For the proposed NFIT method, separate E- and H-field probes are designed and fabricated which operates in both radar range frequency bands of $1.2-1.4 \mathrm{GHz}$ and $2.7-3.1 \mathrm{GHz}$ (probe design and fabrication details in Section 3.1). The E- and H-field probes are designed to produce the minimum level of $600 \mathrm{~V} / \mathrm{m}$ and $1.59 \mathrm{~A} / \mathrm{m}$ on the surface of the steel plate respectively in both frequency bands, with the lower level of power supply from the input source. The magnetic field levels are determined for the far-field condition of E-field levels i.e., $H_{\text {level }}=E_{\text {level }} / \eta$, where $\eta$ is the wave impedance in the far-field region. For the desired target E-field level of $600 \mathrm{~V} / \mathrm{m}$, the corresponding H-field level will be $1.59 \mathrm{~A} / \mathrm{m}$.

The verification of the proposed NFIT debugging method is done as per the flow chart of Figure 3. Firstly, the DUT is tested in an anechoic chamber for the two frequency bands of radar pulse using Figure 1 setup. The frequency and injecting EM wave amplitude levels at which DUT did not comply the qualification requirements (pop-up of error code) are noted. Next, the immunity of the DUT is tested using the proposed NFIT setup and the performance of the DUT is monitored by observing the change in the various input/output signals of the DUT. The variations in the DUT performance are noted in the form of change in observing signals levels/shapes or pop-up of an error code that depicts the immunity of the DUT to that frequency or EM field level. After that, the output of both test setups is compared. The comparison suggests the experimental verification of the proposed NFIT method if the similar behavior (disturbance in the device performance) is noted between the two setups output. Once validated, the proposed NFIT method could be used for the fast debugging of the DUT to perform the root-cause analysis with handy experimental setup in a laboratory environment at a lower cost as compared to repeating the same experimental procedure in the costly and time-consuming far-field test setup of Figure 1.

\section{Design and Fabrication of the Near-Field Electric and Magnetic Field Probes}

This section describes the design, fabrication, and experimental validation results of the proposed near-field electric and magnetic field probes.

\subsection{Electric Field Probe}

\subsubsection{Design and Simulation}

The target of the E-field probe design is to provide the electric field level of $600 \mathrm{~V} / \mathrm{m}[9,10]$ near the probe in the two frequency bands of $1.2-1.4 \mathrm{GHz}$ and $2.7-3.1 \mathrm{GHz}$, respectively. The size of the probe should be moderate (around $15 \mathrm{~cm}$ to $20 \mathrm{~cm}$ ) and to be handy for being used in the proposed NFIT setup. Among the many types of E-field antennas [12-19] L-probe fed circular patch antenna (for brevity onward as L-probe antenna) was chosen because of its relatively simpler geometry, small size, and wideband characteristics $[20,21]$. The L-probe antenna used in this study is an enhanced version of monopolar wire patch antenna $[14,15,20,22]$ which broadens its bandwidth. 
Figure 4a shows the structure of the proposed L-probe antenna and its design parameters. Each parameter in Figure 4a can be calculated as: $H=0.092 \lambda_{0}, R=0.179 \lambda_{0}, r=0.164 \lambda_{o}, d=0.011 \lambda_{0}$, $h=0.079 \lambda_{o}, l=0.131 \lambda_{o}, r_{1}=0.003 \lambda_{o}, t=0.0015 \lambda_{o}, G R=0.357 \lambda_{o}$, and $G T=0.006 \lambda_{o}[20,21]$, where $\lambda_{o}$ is the free space wavelength at the resonance frequency.

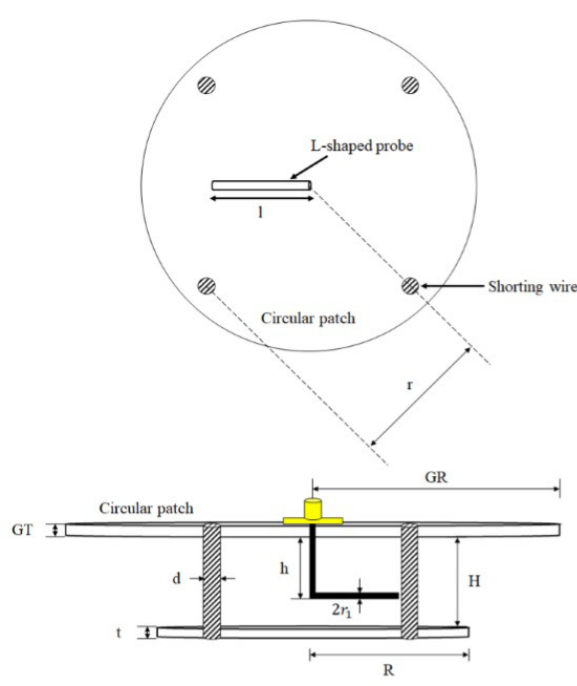

(a)

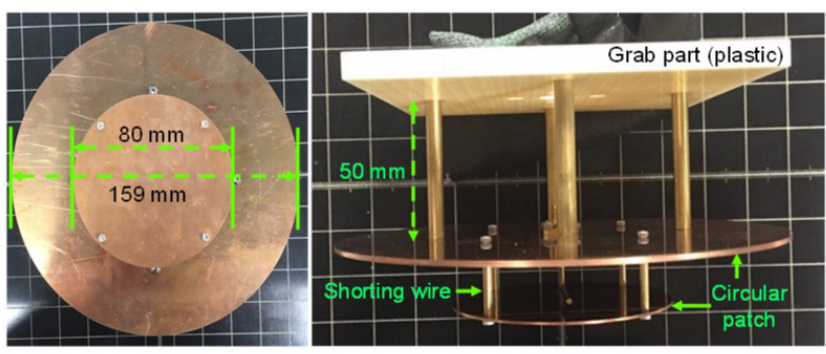

(b)

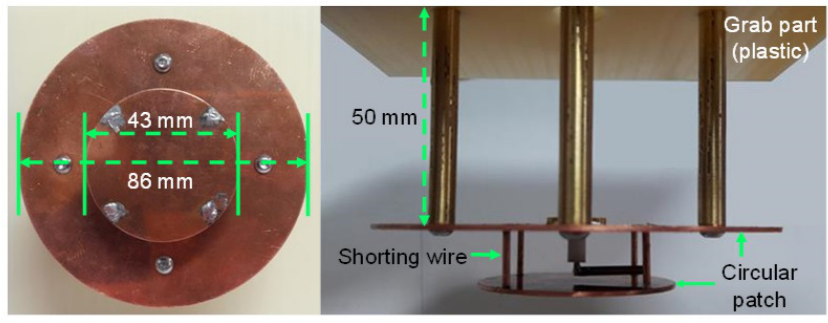

(c)

Figure 4. Design of proposed E-field probe (L-fed circular patch antenna): (a) Geometry and design parameters; (b) Photograph of the fabricated E-field probe for 1.2-1.4 GHz range (1st E-probe); and (c) Photograph of the fabricated E-field probe for 2.7-3.1 GHz range (2nd E-probe).

Table 2. Designed parameters of the two fabricated E-field probes of Figure $4 b, c$ (all units in mm).

\begin{tabular}{cccccccccc}
\hline Design Parameters & $\boldsymbol{H}$ & $\boldsymbol{R}$ & $\boldsymbol{r}$ & $\boldsymbol{d}$ & $\boldsymbol{h}$ & $\boldsymbol{l}$ & $\boldsymbol{r}_{\mathbf{1}}$ & $\boldsymbol{t}$ & $\boldsymbol{G R}$ \\
\hline $1.2-1.4 \mathrm{GHz}$ & 20.5 & 40 & 36.5 & 3 & 17.9 & 29.5 & 1 & 1 & 79.5 \\
$2.7-3.1 \mathrm{GHz}$ & 11 & 21.5 & 19.6 & 0.75 & 10 & 16 & 1 & 1 & 43 \\
\hline
\end{tabular}

For the 1st E-probe, which operates between 1.2 to $1.4 \mathrm{GHz}, \lambda_{o}$ is $230.6 \mathrm{~mm}$ at $1.3 \mathrm{GHz}$. Please note that $1.3 \mathrm{GHz}$ is the center frequency of the resonant band. For the 2nd E-probe working in the range of $2.7-3.1 \mathrm{GHz}$, the resulting $\lambda_{o}$ value is $103.4 \mathrm{~mm}$ at $2.9 \mathrm{GHz}$. With these center frequencies, the probe parameters can be calculated by using the aforementioned relationships. Table 2 summarizes the designed parameters for the two fabricated E-field probes of Figure $4 b, c$.

Each part of designed E-field probes was fabricated by phosphor bronze and assembled through bolts and nuts, and then soldered to form the shown photograph in Figure $4 b, c$, respectively. Due to the limitations of the employed fabrication techniques, the design parameters need to be modified a little bit from the actual calculated designed parameters. For example, a metal plate with a thickness $\left(t=0.0015 \lambda_{o}\right)$ of $0.35 \mathrm{~mm}$ and $0.2 \mathrm{~mm}$ was required for manufacturing the 1st- and 2nd-probe, respectively, as per the design calculations. However, for both cases, the metal plate with thickness of $1 \mathrm{~mm}$ was actually used to fabricate the E-field probes. This is due to the fact that such a thin metal plate tends to be easily torn or bent during processing. Therefore, optimization was carried out to facilitate the actual production and minimizing the performance degradation as much as possible. Table 2 presents the dimensions of the actually fabricated probe geometries keeping in view the manufacturing constraints.

To analyze the field strength of the designed E-field probes, 3D electromagnetic field simulation was performed using ANSYS HFSS as per the schematic diagram of Figure 5a. Figure $5 \mathrm{~b}$ shows the simulation set up in HFSS. The bottom of the probe is located $50 \mathrm{~mm}$ above the metal plate which 
corresponds to the ground of DUT, and the size of the metal plate is $400 \mathrm{~mm}$ by $400 \mathrm{~mm}$ wide in this simulation. These dimensions of the conductive plate are set as the rational dimensions of a typical table used for the RI testing. The E-field levels are recorded at the center cross section of the plate shown in Figure 5a. FU region defined in Figure 5a is the region for which the generated E-field levels by the designed probe are greater than the target E-field level of $600 \mathrm{~V} / \mathrm{m}$.

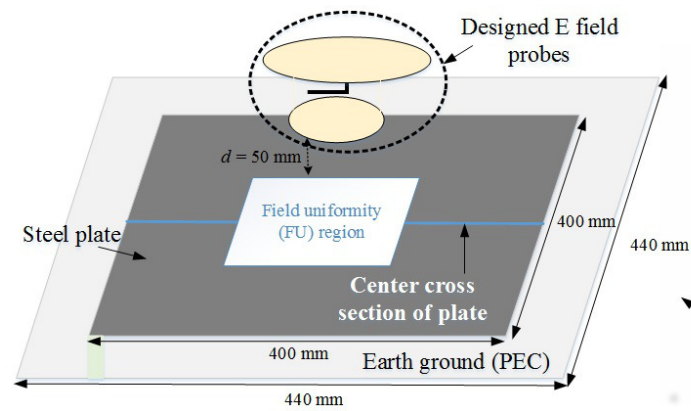

(a)

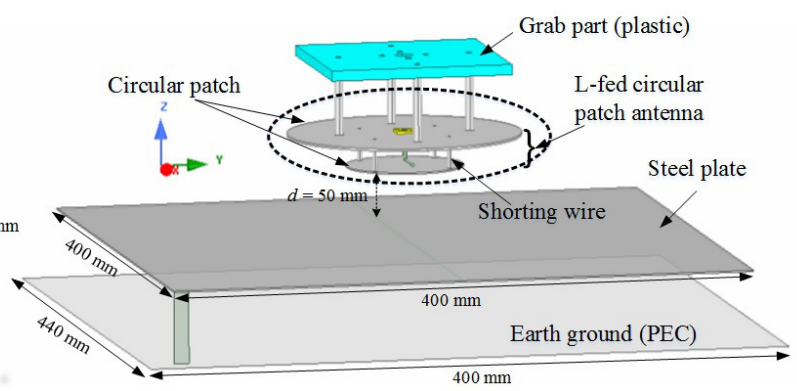

(b)

Figure 5. Simulation setup for NFIT method: (a) Schematic design; and (b) HFSS simulation setup with designed E-field probes.

Figure 6 shows the simulated E-field distribution on the steel plate at the center frequency of each band, i.e., $1.3 \mathrm{GHz}$ and $2.9 \mathrm{GHz}$, respectively. Figure 7 illustrates the simulated E-field intensity at the center cross section of the steel plate with an input power of $12 \mathrm{~W}$. One can see the minimum area above $600 \mathrm{~V} / \mathrm{m}$ (also referred as the FU region in this study) is around $76 \mathrm{~mm}$ wide for the 1st probe, and $51 \mathrm{~mm}$ for the 2nd probe, respectively. These results show that the developed E-probes can produce the E-field level required for the RI debugging of the device using the proposed NIFT setup.

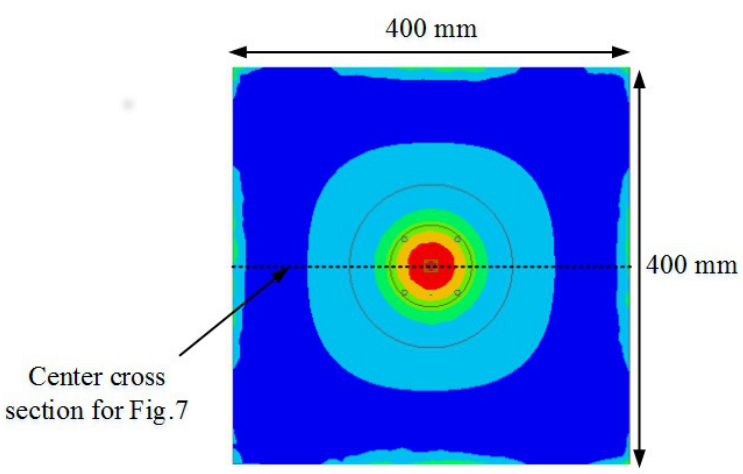

(a)

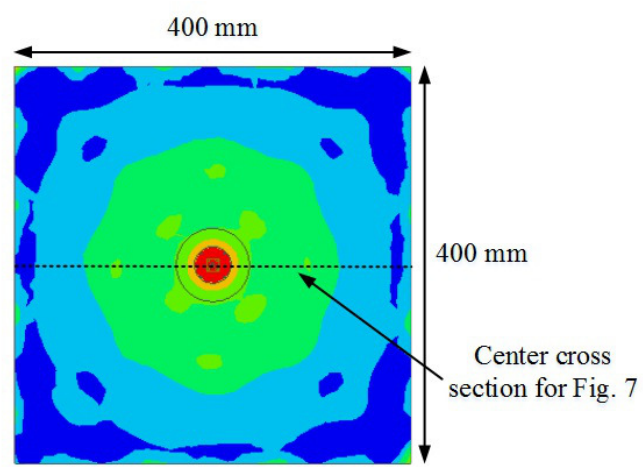

(b)

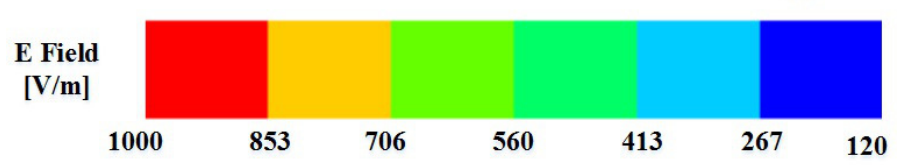

Figure 6. Simulated E-field distribution with input power of $12 \mathrm{~W}$ (a) L-probe antenna for 1.2-1.4 GHz at the center frequency of $1.3 \mathrm{GHz}$ (1st E-probe); and (b) L-probe antenna for 2.7-3.1 GHz at the center frequency of $2.9 \mathrm{GHz}$ (2nd E-probe).

\subsubsection{Comparison of Simulation and Measured Results}

Figure 8 compares the measured and simulated $S$-parameters to check the performance of the designed and fabricated E-probes. Figure $8 \mathrm{a}$ is the experimental setup for $S$-parameter measurement and Figure $8 b, c$ shows the comparison of the measured and simulated $S$-parameters of both fabricated E-field probes. Please note that the probe is located above $50 \mathrm{~mm}$ from the ground plane (as with the simulation setup of Figure 5b) which is made of steel as depicted in Figure 8a. Figure 8b depicts 
the comparison of the simulated and measured reflection coefficient i.e., $S_{11}$ of the 1st E-probe while the comparison of the $S_{11}$ results of the 2nd E-probe is illustrated in Figure 8c. The dashed line in both Figures $8 \mathrm{~b}, \mathrm{c}$ represents the $-10 \mathrm{~dB}$ limit of the $S_{11}$ parameters. These results demonstrate that the measured and simulated $S$-parameters coincide quite well for both E-probes. Also, the reflection coefficient of both designed E-probes is less than $-10 \mathrm{~dB}$ limit for their operational frequency bands of 1.2 to $1.4 \mathrm{GHz}$ and 2.7 to $3.7 \mathrm{GHz}$, respectively.

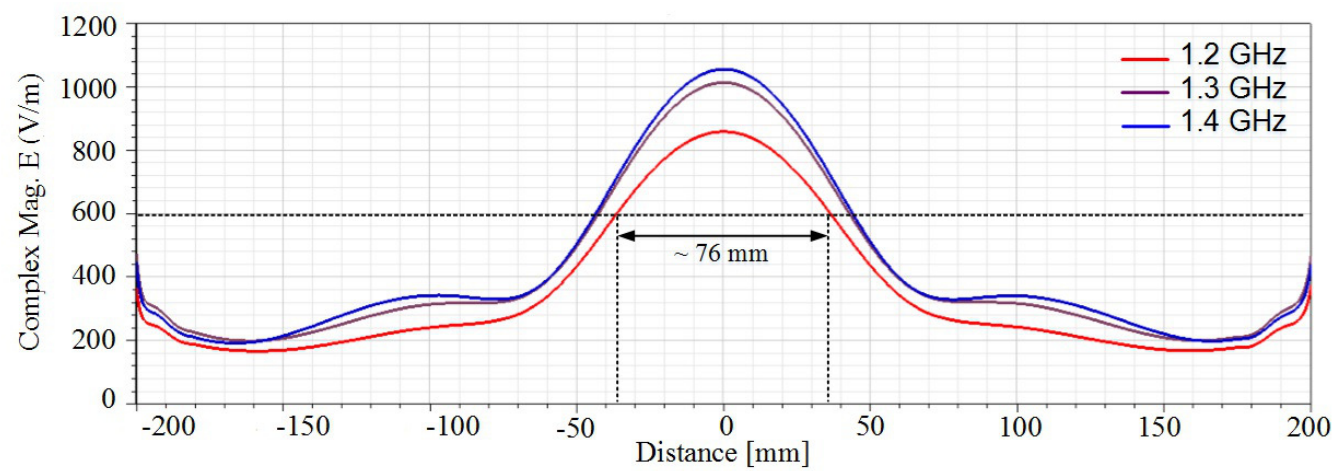

(a)

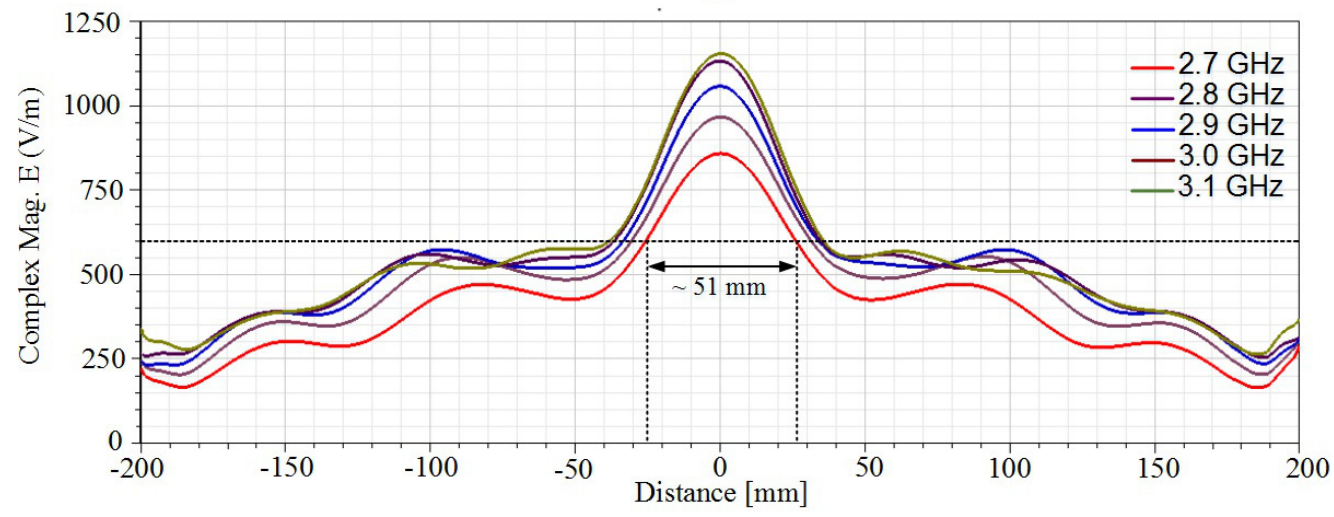

(b)

Figure 7. Simulated E-field intensity on the metal surface at the center cross section of the steel plate with input power of $12 \mathrm{~W}$ (a) L-probe antenna for 1.2-1.4 GHz range (1st E-probe); and (b) L-probe antenna for 2.7-3.1 GHz range (2nd E-probe).

\subsection{Magnetic Field Probe}

\subsubsection{Design and Simulation}

The conventional loop [23-27] or helical/helix shaped [28-30] antennas used as magnetic field antennas cannot produce the required high magnetic field intensity with the constraint of the low input feed power for the near-field magnetic field testing as per the NFIT setup of Figure 2. The embedding of high permeability materials such as ferrites in the antenna structure (sandwiching between the antenna radiator and ground plane as in $[31,32]$ ) could enhance the intensity of the generated magnetic field by the antenna. However, it turned out that even such antennas did not generate the required H-field level for the proposed NFIT setup (see Figure 2) with the presence of a large ground plane under the antenna radiator in the near-field test setup with the supply of the low level of the input power from a signal generator. Also, the limitation of the high frequency EM characteristics of ferrite materials and the increase of the antenna size and weight for [31,32] structures makes them unsuitable for the suggested NFIT setup. 


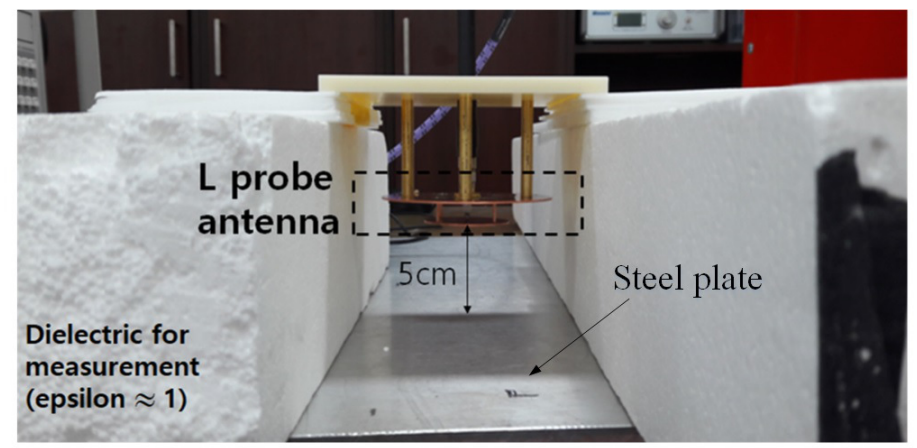

(a)

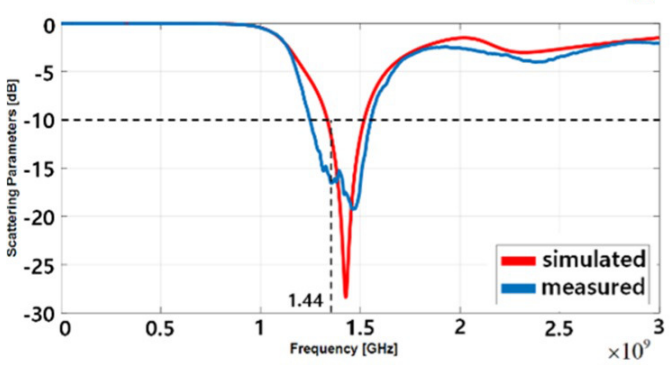

(b)

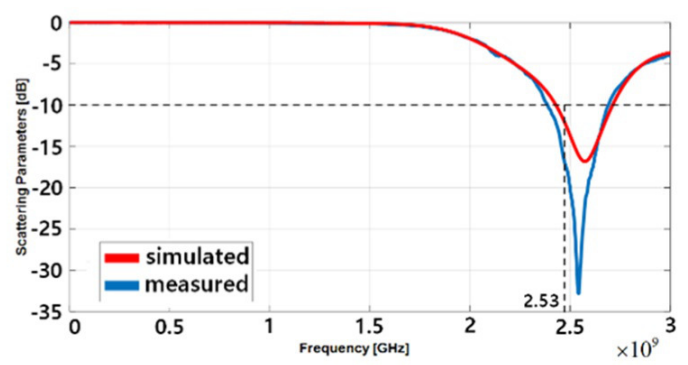

(c)

Figure 8. Comparison of the measured and simulated $S$-parameters: (a) Experiment setup for the $S$-parameters measurements; (b) S-parameters of L-probe antenna for 1.2-1.4 GHz (1st E-probe); and (c) $S$-parameters of L-probe antenna for 2.7-3.1GHz (2nd E-probe).

To meet the requirements of magnetic field intensity in the near-field region with a steel plate under the DUT along with the constraint of minimal input power, a printed square loop antenna is designed as the magnetic field probe [33]. Figure 9 illustrates the designed magnetic field probe. The probe is fed with a co-planar waveguide (CPW) feed structure. The designed probe is backed by a partial ground plane as illustrated in Figure $9 \mathrm{~b}$. The dimensions of the ground plane are optimized with the trial-and-error technique to achieve the desired performance of the $\mathrm{H}$-field probe.

The designed magnetic field probe is simulated as per the simulation setup of Figure 10 using HFSS simulator. The distribution of the magnetic field at the steel plate is shown in Figure 11 for the designed $\mathrm{H}$-field probe with the input power of $15 \mathrm{~W}$. It illustrates that the level of the magnetic field intensity on the top of the ground plane away from the $\mathrm{H}$-field probe is quite uniform and the magnitude levels are above the desired limit level of $1.59 \mathrm{~A} / \mathrm{m}$ even with $15 \mathrm{~W}$ input power.

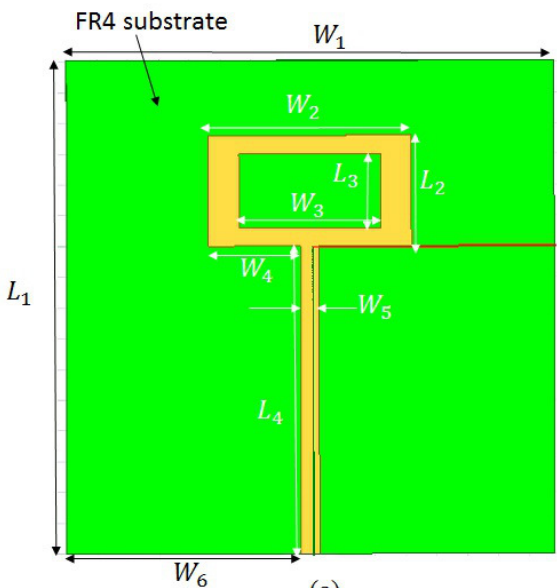

(a)

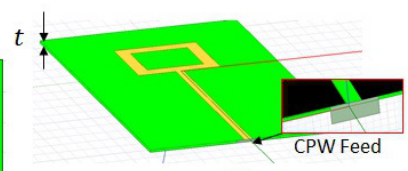

(c)

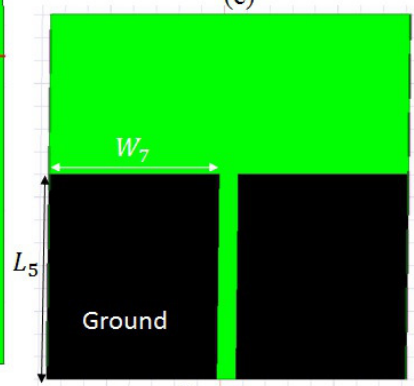

(b)

Figure 9. Designed magnetic field probe: (a) Top view; (b) Bottom view; and (c) 3D view ( $L_{1}=80 \mathrm{~mm}$, $L_{2}=18 \mathrm{~mm}, L_{3}=12 \mathrm{~mm}, L_{4}=50 \mathrm{~mm}, L_{5}=45 \mathrm{~mm}, W_{1}=80 \mathrm{~mm}, W_{2}=33 \mathrm{~mm}, W_{3}=23 \mathrm{~mm}, W_{4}=15 \mathrm{~mm}$, $W_{5}=3 \mathrm{~mm}, W_{6}=38 \mathrm{~mm}, W_{7}=37.4 \mathrm{~mm}$, and $\left.t=1.53 \mathrm{~mm}\right)$. 


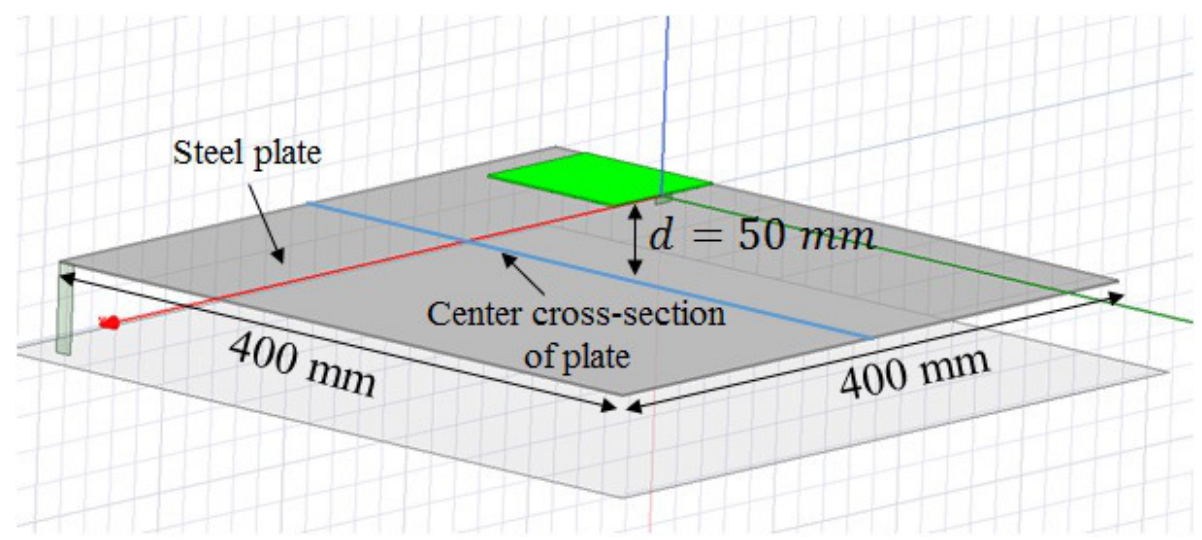

Figure 10. HFSS simulation setup of magnetic field probe with $d=5 \mathrm{~cm}$.

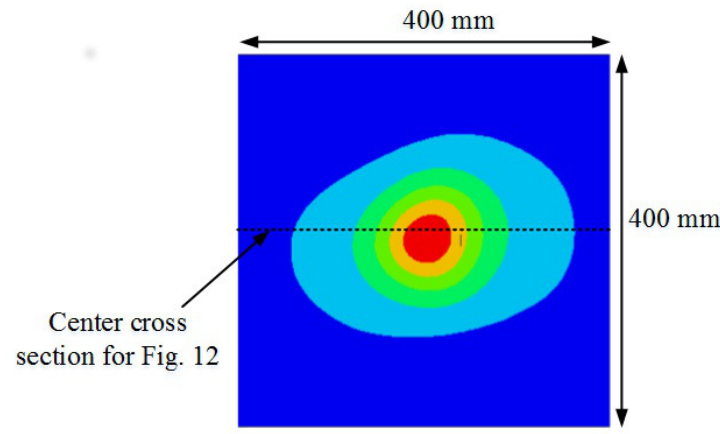

(a)

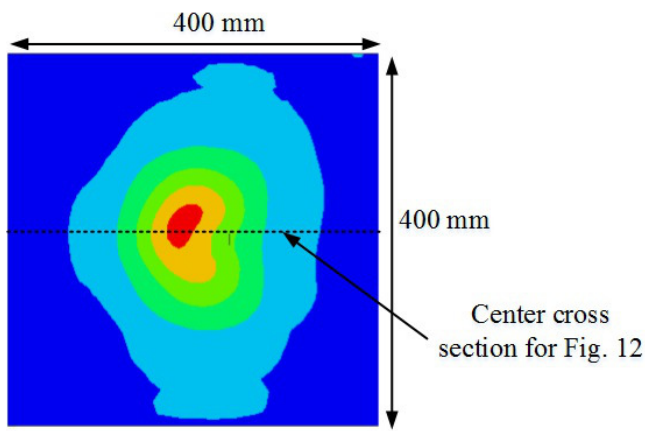

(b)

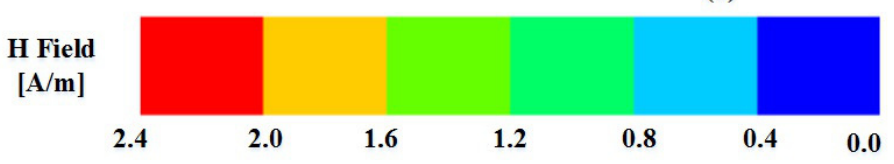

Figure 11. Simulated $\mathrm{H}$-field distribution with input power of $15 \mathrm{~W}$ (a) $\mathrm{H}$-field probe for 1.2-1.4 GHz at the center frequency of $1.3 \mathrm{GHz}$, (b) H-field probe for $2.7-3.1 \mathrm{GHz}$ at the center frequency of $2.9 \mathrm{GHz}$.

The objective of the designing of the $\mathrm{H}$-field probe was to produce the desired level of the magnetic field on the surface of the ground plane. Please note that only one probe was used to generate the required magnetic field strength in both 1.2-1.4 GHz and 2.7-3.1 GHz ranges. The simulated results of the recorded magnetic field levels on the center cross section of the ground plane are shown in Figure 12 for the input power of $15 \mathrm{~W}$. Figure 12a,b show the cross-sectional magnetic field results for the frequency range of 1.2 to $1.4 \mathrm{GHz}$ and 2.7 to $3.1 \mathrm{GHz}$, respectively. The results show that the designed magnetic field probe produces the quite uniform magnetic field with around $104 \mathrm{~mm}$ FU value in the first frequency band (i.e., 1.2-1.4 GHz) and approximately $35 \mathrm{~mm}$ to $75 \mathrm{~mm}$ in the high frequency band of 2.7 to $3.1 \mathrm{GHz}$, respectively. It can be observed from Figure 12a that in the first radar pulse frequency band the observed level of the H-field magnitude is higher than $1.59 \mathrm{~A} / \mathrm{m}$ (corresponding to the E-field level of $600 \mathrm{~V} / \mathrm{m}$ ) for the approximate range of $104 \mathrm{~mm}$. Furthermore, the observed field uniformity region for the higher band of radar pulse frequency band ranges from 35 to $75 \mathrm{~mm}$ as depicted in Figure 12b. The results of Figure 12 explains that the designed magnetic field probe can even generate a high level of the magnetic field $(>1.59 \mathrm{~A} / \mathrm{m})$ with the small power feeding from the signal generator. These results demonstrate that unlike the need for two E-field probes, the only one designed H-field probe could be used for the RI debugging in both the radar pulse frequency bands. 


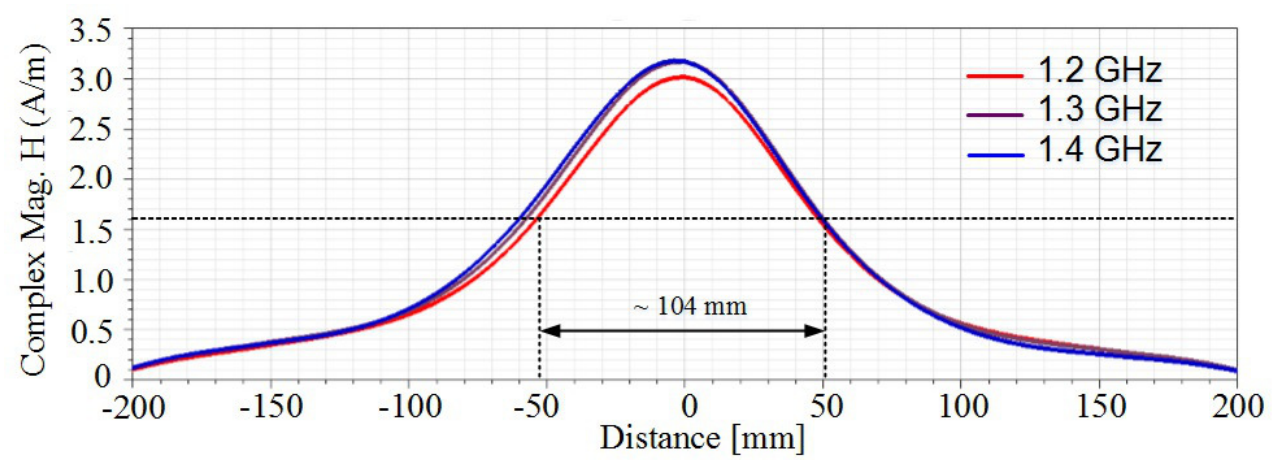

(a)

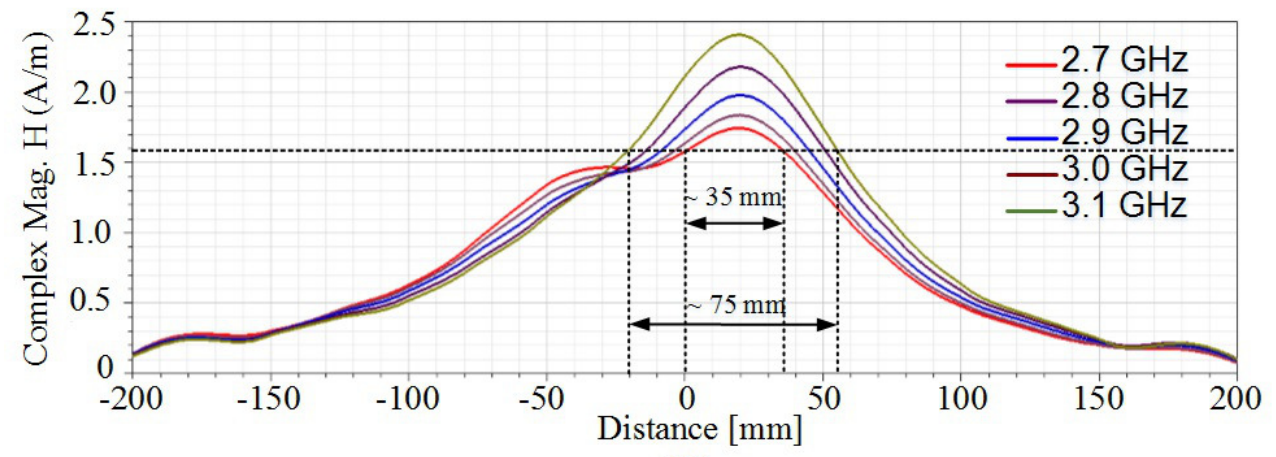

(b)

Figure 12. Simulated $\mathrm{H}$-field intensity on the metal surface at the center cross section of the steel plate with input power of $15 \mathrm{~W}$ (a) Field levels for 1.2-1.4 GHz range, (b) Field levels for 2.7-3.1 GHz range.

\subsubsection{Comparison of Simulation and Measured Results}

Figure 13a shows the photograph of the manufactured magnetic field probe. The measurements of the S-parameters are carried out as per the NFIT simulation setup of Figure 10 and the measurement setup picture is shown in Figure 13b. The comparison of simulated and measured S-parameters of the $\mathrm{H}$-field probe is depicted in Figure 13c. The results show the good agreement between the simulated and measured $S$-parameters of the field probe. Also, it can be noted from Figures $13 \mathrm{c}$ and $12 \mathrm{~b}$ that even with the return loss values of around $-5 \mathrm{~dB}$ in the high frequency band of 2.7 to $3.1 \mathrm{GHz}$, the designed $\mathrm{H}$-field probe can generate the desired intensity of magnetic field as illustrated in Figure 12b.

The good agreement between the simulation and measured results of designed E- and H-field probes confirm that both probes could be used as an authentic radiated immunity source for the near-field immunity testing of DUT. Although both probes are designed with the higher limit values of electric and magnetic fields i.e., $600 \mathrm{~V} / \mathrm{m}$ and $1.59 \mathrm{~A} / \mathrm{m}$ respectively, their driven power is around 12 to $15 \mathrm{~W}$. The input power requirements could be further lowered to around $8-10 \mathrm{~W}$ for both probes if the RI debugging of the electronic device is required in the specified lower limit region of $300 \mathrm{~V} / \mathrm{m}$ (0.79 A/m for H-field) of Ford requirements [10] as shown in Table 1. 


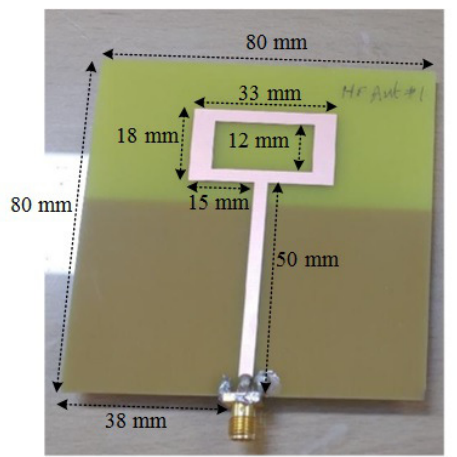

(a)

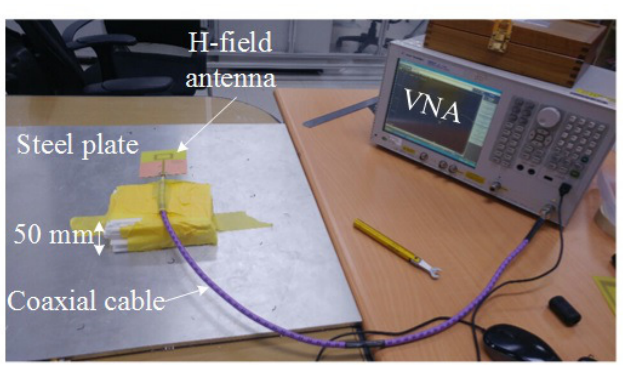

(b)

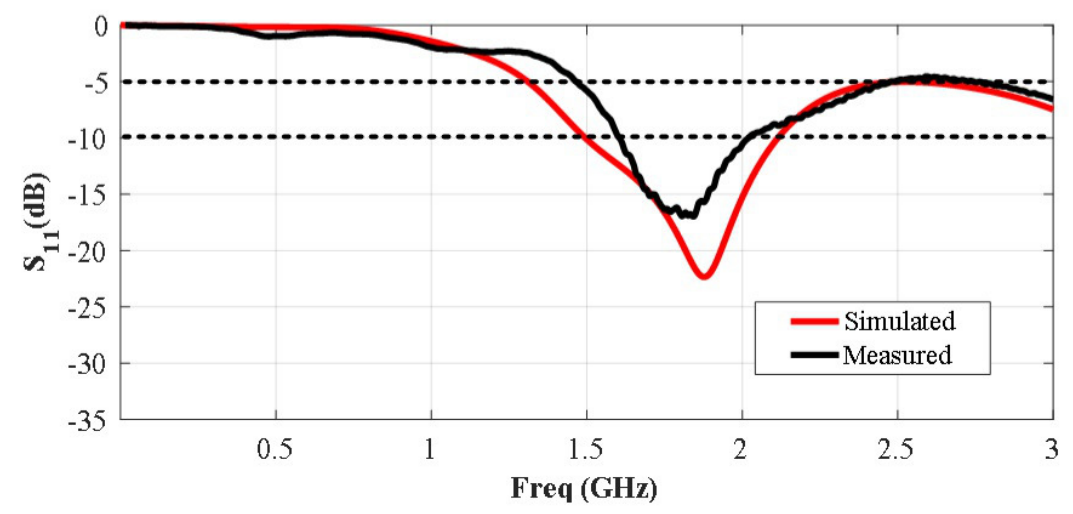

(c)

Figure 13. Fabricated H-field probe and S-parameter results: (a) Photograph of manufactured probe; (b) Picture of measurement setup for the $S$-parameter measurements of designed H-field probe; and (c) Comparison of simulated and measured $S$-parameters.

\section{Validation of Proposed NFIT Setup}

In this section, we analyze the immunity characteristic of a specific automotive industry electronic DUT in the frequency range of 1.2-1.4 GHz, using both the ISO 11452-2 far-field test and the proposed NFIT method for the verification of the suggested approach. In ISO 11452-2 test, error codes (previously stored in the equipment) are recorded during the test which shows the disturbance in the working state of the DUT in case of the low immunity. Subsequently, low immunity states (frequency/E-field levels where error code pops up) of the chosen DUT are recorded and noted for the further validation of the proposed NFIT method. After that, the RI debugging of the automotive electronic device is performed using the proposed NFIT method to demonstrate the validity of the proposed method as per the flow chart of Figure 3.

\subsection{Device Under Test}

The used vehicle DUT for the case study analysis was an EPS device. Figure 14 shows a schematic of a complete steering system in a typical contemporary car [34]. The EPS is used for the easy and effortless steering in the advanced vehicles with the enhancement of the fuel efficiency. EPS helps the drivers to steer the vehicle by augmenting steering effort of the steering wheel. It provides an appropriate state of the steering by changing the condition of the oil pressure depending on the steering state and speed of the vehicle. 


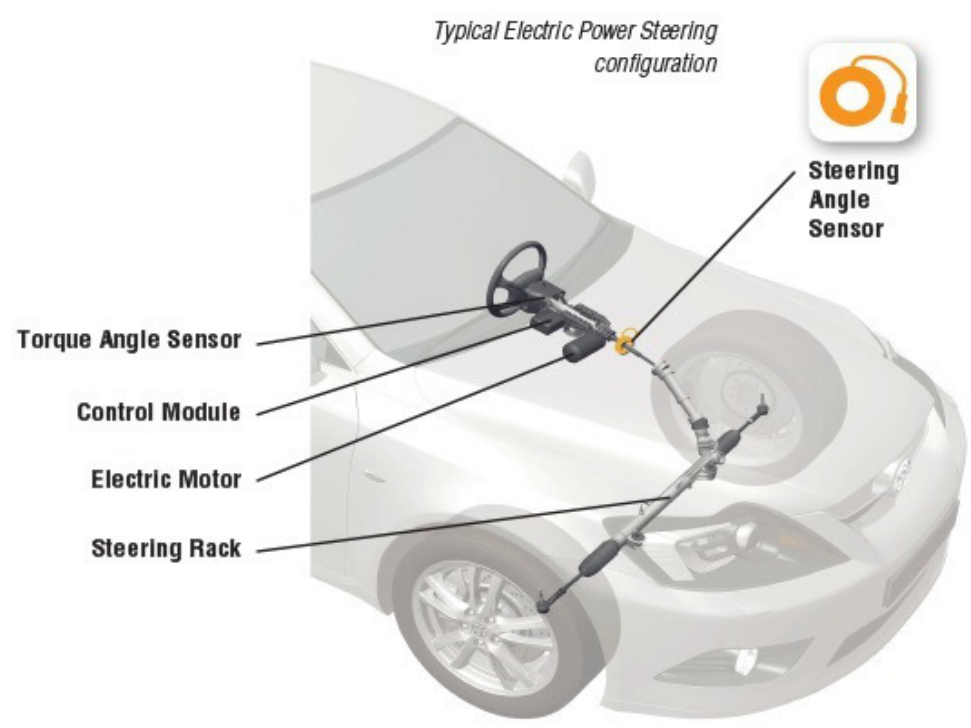

Figure 14. Steering system of a typical modern era vehicle [34].

Most EPS consist of many electric components which includes electric actuators, micro controller, electronic control unit (ECU) and different kinds of sensors for the monitoring of the steering angle, steering torque, vehicle speed, and wheel position. Based on the sensor inputs, ECU adjusts the required assistance by all components for effortless steering by the driver.

Monitoring the temperature of EPS printed circuit board (PCB) which integrates the different electrical parts of EPS is one of the ways to check the EPS operation during the RI testing. The circuit of Figure 15 shows a typical temperature integrated circuit (IC) mounted on the EPS for the monitoring of the DUT performance. In Figure 15, 'VOUT' is the analog voltage which includes temperature information. The output of this IC i.e., 'ADC_TEMP' is connected to micro controller.

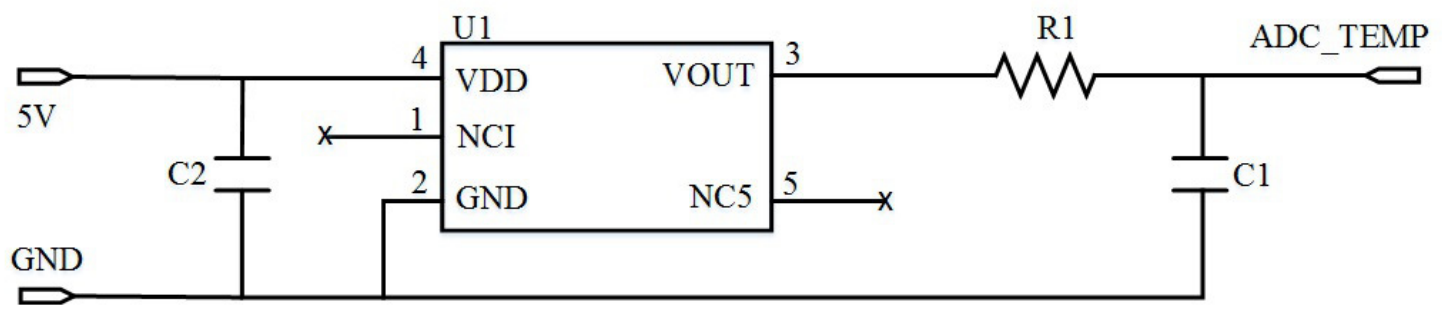

Figure 15. A typical temperature monitoring IC of EPS.

\subsection{E-Field Immunity Testing}

Figure 16a shows the picture the complete laboratory bench measurement setup for the RI debugging of the used EPS DUT using the proposed NFIT method. The fabricated E-field probe (L-probe fed antenna) is placed $50 \mathrm{~mm}$ away from the DUT as illustrated in Figure 16a,b. The transmit probe is fed from an RF signal generator. The performance of the different functionalities of the EPS device is monitored by attaching the monitoring harness to the PCB of the DUT. It should be pointed out that as compared to the far-field test setup of [11], in the proposed setup of Figure 16, monitoring harness is not directly exposed to the E-field of the transmit probe due to its small size. Here, the phase center of the E-field probe is aligned to EPS DUT and it only illuminates it. This approach prevents the direct coupling of the strong E-field to the monitoring harness which could results in wrong recoding of error code corresponding to the low susceptibility condition. The monitoring harness is attached to the DUT monitoring tool (a software-based system on a laptop) as illustrated in Figure 16a. This system records the abnormalities in the different signals of the PCB and shows the error code when the DUT becomes susceptible to the exposing high-intensity E- or H-field levels. 


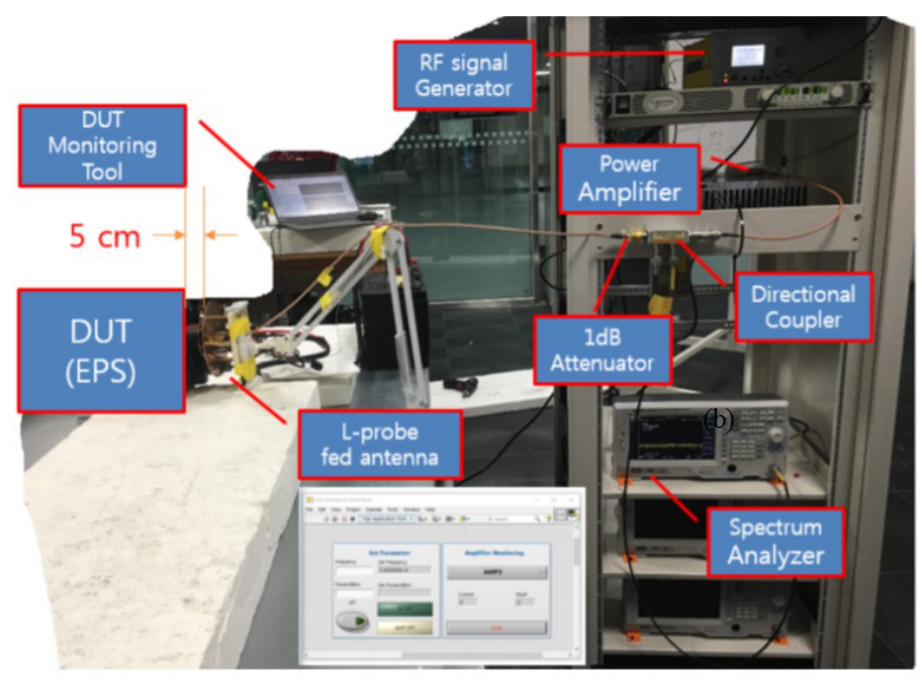

(a)

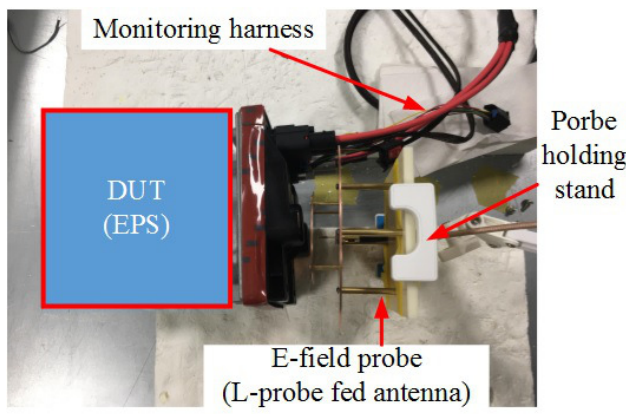

(b)

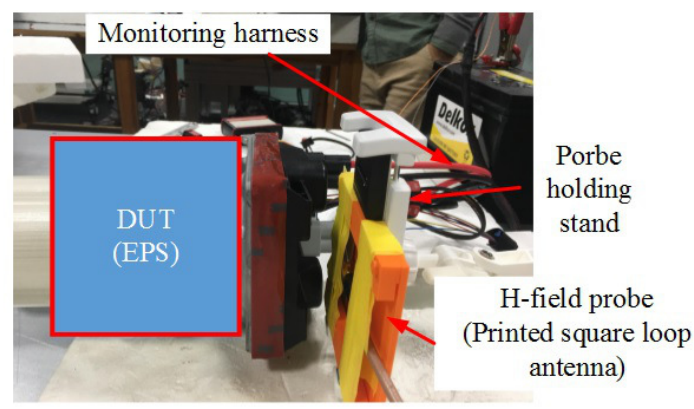

(c)

Figure 16. NFIT setup for the RI debugging of a specific automotive industry electronic DUT (EPS) (a) Complete laboratory bench test description of the proposed NFIT RI setup; (b) Photograph of the E-field probe and DUT (probe is $50 \mathrm{~mm}$ away from DUT); and (c) Photograph of the H-field probe and DUT (probe is $50 \mathrm{~mm}$ away from DUT).

Figure 17a shows the induced voltage waveform in the analog-to-digital converter (ADC) signal of the EPS PCB when the near-field E-field probe driven by $12 \mathrm{~W}$ input power illuminates the EPS. It is good to check that the error code was also stored in the equipment. Both the disturbance in the induced voltage in the PCB of DUT and the error code popped up clearly which means that this specific DUT is susceptible to the electric field of around $600 \mathrm{~V} / \mathrm{m}$ from the E-probe. We suspect that the trace between the temperature IC and micro controller of Figure 15 as the coupling path of the injected noise which disturbs the output the IC and thus the performance of the EPS. The same DUT was also tested in ISO 11452-2 environment, and the same error code popped up. Therefore, we could say that both methods successfully produced similar results about the immunity characteristics of the DUT in the frequency range of 1.2 to $1.4 \mathrm{GHz}$, at least in quality, even though not in quantity. After the test, the DUT was carefully investigated to find the weak point of PCB, and the circuit in PCB was repaired accordingly. Then the test was repeated with near-field E-probe, and we found that no error code popped up in the equipment. Furthermore, we also found that the induced voltage in DUT has almost disappeared as shown in Figure $17 \mathrm{~b}$ results.

\subsection{H-Field Immunity Testing}

After the E-field RI immunity test, magnetic field RI immunity testing of the EPS DUT is performed by replacing the E-field probe with the fabricated H-field probe as illustrated in Figure 16c. The H-field 
probe illuminates the DUT with an approximate magnetic field level of $1.59 \mathrm{~A} / \mathrm{m}$ with the input power of $15 \mathrm{~W}$ from the RF signal generator. As like the E-field susceptibility results of the DUT (see Figure 17), similar induced voltage and error-code popping results are noted with the H-field transmit probe as depicted in Figure 18a. Subsequently, the change are made in the EPS DUT and the test is repeated. Figure $18 \mathbf{b}$ shows that the EPS DUT is not susceptible to the incident H-field after the modification.

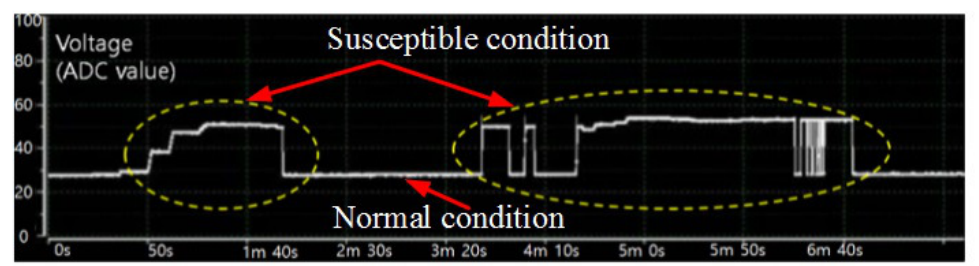

(a)

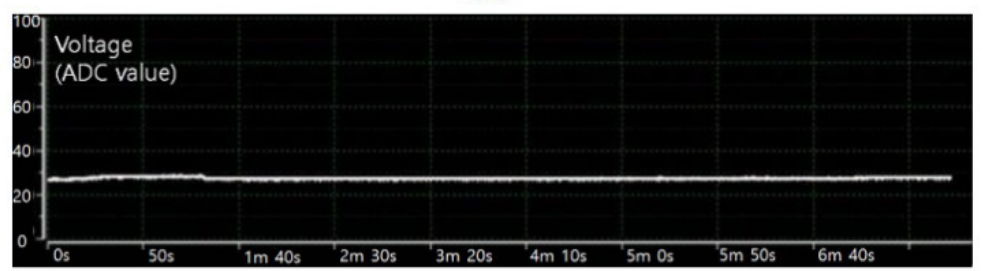

(b)

Figure 17. Performed NFIT RI results for a specific automotive industry electronic DUT with E-field probe (see Figure 16b): (a) Induced voltage in PCB with near-field E-probe driven by $12 \mathrm{~W}$ input power (error debugging); and (b) Induced voltage in PCB after circuit modification (error rectification) with near-field E-probe is driven by same $12 \mathrm{~W}$ input power.

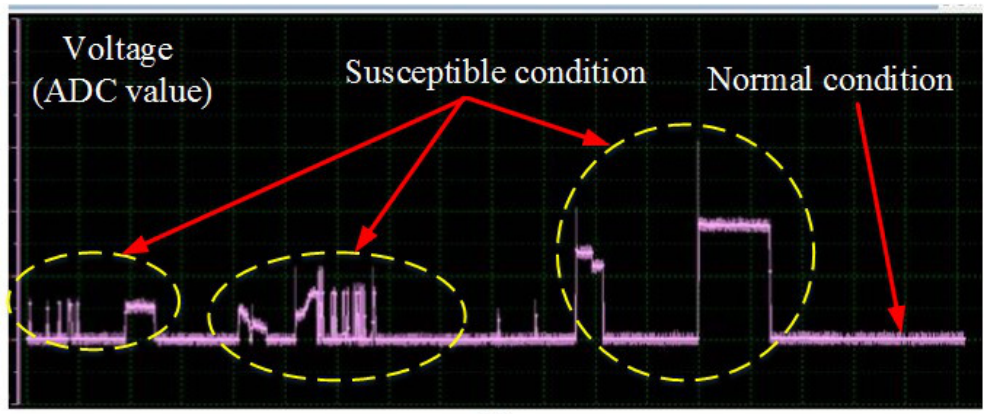

(a)

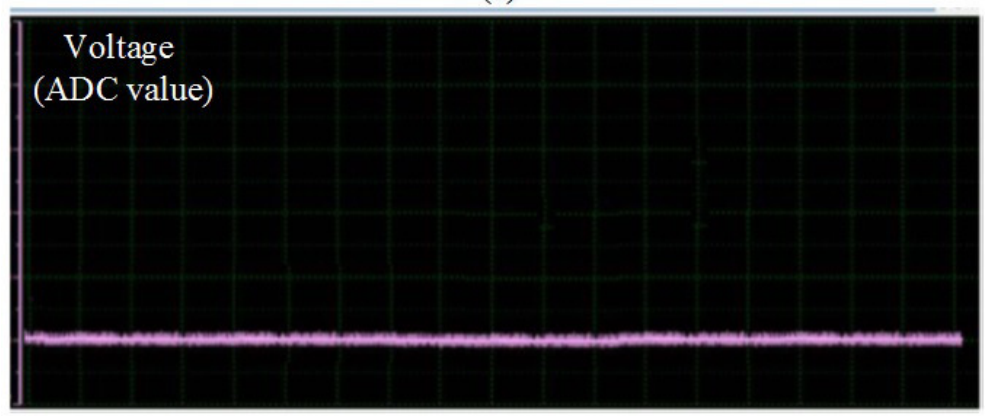

(b)

Figure 18. Performed NFIT RI results for a specific automotive industry electronic DUT with H-field probe (see Figure 16b): (a) Induced voltage in PCB with near-field $\mathrm{H}$-field probe driven by $15 \mathrm{~W}$ input power (error debugging); and (b) Induced voltage in PCB after circuit modification (error rectification) with $\mathrm{H}$-field probe driven by same $15 \mathrm{~W}$ input power. 
Table 3 summarizes a comparison of the two immunity test methods. As can be seen in the table, the proposed near-field immunity method requires much less input power (no need for high-power $300 \mathrm{~W}$ to $1000 \mathrm{~W}$ amplifiers), and the signals in DUT can be seen during the test, which helps the debugging process quite efficient, still producing the same immunity result as the ISO 11452-2 test in this specific DUT. Also, as the designed E/H-field probes only illuminate the testing DUT, the proposed setup did not need optical cable harness to minimize the direct effect of injecting EM waves on the DUT attached harness as needed in ISO 11452-2 for the same. It should be mentioned here, again, that the proposed NFIT method did not quantify the EMC quality compliance testing of the automotive electronic DUT as per the requirements of $[9,10]$. It just acts as a handy useful industry experimental tool to quickly debug the errors in the functionality of the electronic device with the real-time monitoring of the performance signals and, hence, its fast repairing and error rectification, which offers the additional advantages of the rapid production and lesser time to market of the product.

Table 3. Comparison of the two immunity test methods.

\begin{tabular}{cccccc}
\hline & \multicolumn{2}{c}{$\begin{array}{c}\text { Distance between } \\
\text { Antenna and DUT }\end{array}$} & $\begin{array}{c}\text { Required Power Signal from } \\
\text { of Amplifier }\end{array}$ & $\begin{array}{c}\text { Eut } \\
\text { DUtor Code }\end{array}$ & Test Results \\
\hline ISO 11452-2 & $\sim 1000 \mathrm{~mm}$ & $\sim 300-1000 \mathrm{~W}$ & Available & Available & $\begin{array}{c}\text { Recording of } \\
\text { susceptible conditions } \\
\text { (error points) }\end{array}$ \\
\hline $\begin{array}{c}\text { Proposed } \\
\text { NFIT Method }\end{array}$ & $\sim 50 \mathrm{~mm}$ & $\sim 8-15 \mathrm{~W}$ & Available & Available & $\begin{array}{c}\text { Successful } \\
\text { reproduction of } \\
\text { susceptible condition }\end{array}$ \\
\hline
\end{tabular}

\section{Conclusions}

The study has proposed a near-field immunity (NFIT) method for the rapid RI debugging of automotive electronics in the radar pulse ranges of 1.2 to $1.4 \mathrm{GHz}$ and 2.7 to $3.1 \mathrm{GHz}$, respectively. For the injection of the high level of E-field $(\geq 600 \mathrm{~V} / \mathrm{m})$ and $\mathrm{H}$-field $(\geq 1.59 \mathrm{~A} / \mathrm{m})$ in the proposed NFIT method, two small-size and handy electric and magnetic field probes are designed and fabricated which can be driven with low input power of around 8 to $15 \mathrm{~W}$, and thus eliminates the need for high-power amplifier ( $300 \mathrm{~W}-1000 \mathrm{~W}$ ) and optical DUT connecting harness requirements as needed in ISO 11452-2 far-field test setup. The proposed RI debugging procedure is validated with the case study RI testing and debugging of an automotive EPS device, as DUT covers both far-field and proposed near-field laboratory test requirements.

The proposed procedure could be used for the fast RI debugging of automotive DUTs in the laboratory environment for rapid identification of any malfunctioning in DUT performance and development of counter-strategy for its correct operation. After that, final OEM qualification testing could be performed in the industrial established far-field test setup of ISO 11452-2. This strategy would help car manufacturers and EMC engineers to speed up the production phase and launch the product quickly in the present competitive environment with the reduction in time and cost of the time to market of the product.

Author Contributions: Conceptualization, J.Y., D.L., J.H., H.L. and W.N.; methodology, J.Y., D.L., J.H. and H.L.; software, J.Y., J.H., H.L., J.K. and M.F.; validation, J.Y., D.L., J.H. and H.L.; formal analysis, J.Y., J.H., H.L., J.K. and M.F.; investigation, J.Y., D.L., J.H., H.L. and M.F.; resources, J.K. M.F. and W.N.; data curation, J.Y., J.H. and M.F.; Writing-Original Draft preparation, J.Y.; Writing-Review and Editing, J.Y., D.L., J.H. and W.N.; visualization, J.Y., J.H. and M.F.; supervision, W.N.; project administration, W.N.; funding acquisition, W.N.

Funding: This work was supported by Industry Collaborative Project between the Sungkyunkwan University and MANDO Corp. Ltd.

Conflicts of Interest: The authors declare no conflict of interest. 


\section{References}

1. Rybak, T.; Steffka, M. AutoMotive Electromagnetic Compatibility (EMC); Springer: Berlin, Germany, 2004.

2. Wang, L.B.; Ma, L.; Koh, E.A. Analyzing the EMC performance of an automotive display module through 3D electromagnetic simulation. In Proceedings of the 2018 IEEE International Symposium on Electromagnetic Compatibility and 2018 IEEE Asia-Pacific Symposium on Electromagnetic Compatibility (EMC/APEMC), Singapore, 14-18 May 2018; pp. 827-830.

3. Guttowski, S.; Weber, S.; Hoene, E.; John, W.; Reichl, H. EMC issues in cars with electric drives. In Proceedings of the 2003 IEEE Symposium on Electromagnetic Compatibility. Symposium Record (Cat. No.03CH37446), Boston, MA, USA, 18-22 August 2003; Volume 2, pp. 777-782. [CrossRef]

4. Zhao, H.; Li, G.; Wang, N.; Zheng, S.; Yu, L.; Chen, Y. Study of EMC Problems with Vehicles. In Information Computing and Applications; Yang, Y., Ma, M., Liu, B., Eds.; Springer: Berlin/Heidelberg, Germany, 2013; pp. 159-168.

5. Huber-Obst, T. Target filtering for military ATC primary radar. In Proceedings of the 2018 19th International Radar Symposium (IRS), Bonn, Germany, 20-22 June 2018; pp. 1-7. [CrossRef]

6. Zhang, L.J. A new generation of S-band solid state $16 \mathrm{~kW}$ transmitter for ATC primary radar. In Proceedings of the 1999 IEEE Radar Conference. Radar into the Next Millennium (Cat. No.99CH36249), Waltham, MA, USA, 22-22 April 1999; pp. 191-193. [CrossRef]

7. Smith, J. Automotive $600 \mathrm{~V} / \mathrm{m}$ Radar Pulse test solution. In Proceedings of the 2006 9th International Conference on Electromagnetic Interference and Compatibility (INCEMIC 2006), Bangalore, India, 23-24 Feburary 2006; pp. 151-154.

8. Kothapudi Venkata Kishore, K.V. Compact $1 \times 2$ and $2 \times 2$ Dual Polarized Series-Fed Antenna Array for X-Band Airborne Synthetic Aperture Radar Applications. J. Electromagn. Eng. Sci. 2018, 18, 117-128. [CrossRef]

9. General Specification for Electrical/Electronic Components and Subsystems; Technical Report GMW3097; Electromagnetic Compatibility: Detroit, MI, USA, 2019.

10. Electromagnetic Compatibility Specification for Electrical/Electronic Components and Subsystems; Technical Report FMC1278; Electromagnetic Compatibility: Detroit, MI, USA, 2012.

11. Road Vehicles_Component Test Methods for Electrical Disturbances from Narrowband Radiated Electromagnetic Energy-Part 2: Absorber-Lined Shielded Enclosure; Technical Report ISO 11452-2; ISO: Geneva, Switzerland, 2004.

12. Kim, J.; Sung, Y. Dual-Band Microstrip Patch Antenna with Switchable Orthogonal Linear Polarizations. J. Electromagn. Eng. Sci. 2018, 18, 215-220. [CrossRef]

13. Yoon, S.J.; Choi, J. A Low-Profile Broadband Array Antenna for Home Repeater Applications. J. Electromagn. Eng. Sci. 2018, 18, 261-266. [CrossRef]

14. Jecko, B.; Decroze, C. THE “Monopolar Wire Patch Antenna” concept. In Proceedings of the Second European Conference on Antennas and Propagation, Edinburgh, UK, 11-16 November 2007; pp. 1-5. [CrossRef]

15. Row, J.S.; Yeh, S.H.; Wong, K.L. A wide-band monopolar plate-patch antenna. IEEE Trans. Antennas Propag. 2002, 50, 1328-1330. [CrossRef]

16. Kong, M.; Shin, G.; Lee, S.H.; Yoon, I.J. Investigation of 3D Printed Electrically Small Folded Spherical Meander Wire Antenna. J. Electromagn. Eng. Sci. 2017, 17, 228-232. [CrossRef]

17. Gaetano, D.; McEvoy, P.; Ammann, M.J.; Brannigan, C.; Keating, L.; Horgan, F. Footwear and Wrist Communication Links using 2.4 GHz and UWB Antennas. Electronics 2014, 3, 339-350. [CrossRef]

18. Mahmud, M.Z.; Islam, M.T.; Almutairi, A.F.; Samsuzzaman, M.; Acharjee, U.; Islam, M.T. A Parasitic Resonator-Based Diamond-Shaped Microstrip Antenna for Microwave Imaging Applications. Electronics 2019, 8, 434. [CrossRef]

19. Yousaf, J.; Jung, H.; Kim, K.; Nah, W. Design, Analysis, and Equivalent Circuit Modeling of Dual Band PIFA Using a Stub for Performance Enhancement. J. Electromagn. Eng. Sci. 2016, 16, 169-181. [CrossRef]

20. Lau, K.L.; Luk, K.M. A wide-band monopolar wire-patch antenna for indoor base station applications. IEEE Antennas Wirel. Propag. Lett. 2005, 4, 155-157. [CrossRef]

21. Guo, Y.X.; Chia, M.Y.W.; Chen, Z.N.; Luk, K.M. Wide-band L-probe fed circular patch antenna for conical-pattern radiation. IEEE Trans. Antennas Propag. 2004, 52, 1115-1116. [CrossRef] 
22. Mok, K.Y.; Rhee, Y.C.; Yoon, J.H. Design of a Pot-Shaped Monopole Antenna with Dual Band Notched Characteristics for UWB Application. J. Electromagn. Eng. Sci. 2017, 17, 44-50. [CrossRef]

23. Yan, Z.; Wang, J.; Zhang, W.; Wang, Y.; Fan, J. A Simple Miniature Ultrawideband Magnetic Field Probe Design for Magnetic Near-Field Measurements. IEEE Trans. Antennas Propag. 2016, 64, 5459-5465. [CrossRef]

24. Petrariu, A.I.; Lavric, A.; Coca, E. Design of an High Frequency RFID Multi-Loop Antenna for Applications in Metallic Environments. Adv. Electr. Comput. Eng. 2018, 18, 35-41. [CrossRef]

25. Chen, C.P.; Sugawara, K.; Li, K.; Nihei, H.; Anada, T.; Christopoulos, C. Non-contacting near-field mapping of planar circuits in microwave frequency band. In Proceedings of the 2008 IEEE International Symposium on Electromagnetic Compatibility, Detroit, MI, USA, 18-22 August 2008.

26. Hur, J.; Byun, G.; Choo, H. Design of Small CRPA Arrays with Circular Microstrip Loops for Electromagnetically Coupled Feed. J. Electromagn. Eng. Sci. 2018, 18, 129-135. [CrossRef]

27. Oh, S.; Jang, B.J.; Chae, H. Sensitivity Enhancement of a Vertical-Type CMOS Hall Device for a Magnetic Sensor. J. Electromagn. Eng. Sci. 2018, 18, 35-40. [CrossRef]

28. Sivaraman, N. Design of Magnetic Probes for Near Field Measurements and the Development of Algorithms for the Prediction of EMC. Ph.D. Thesis, Université Grenoble Alpes, Grenoble, France, 2017.

29. Yousaf, J.; Amin, M.; Iqbal, S. Design of circularly polarized omnidirectional bifilar helix antennas with optimum wide axial ratio beamwidth. Prog. Electromagn. Res. C 2013, 39, 119-132. [CrossRef]

30. Amin, M.; Yousaf, J.; Iqbal, S. Single feed circularly polarised omnidirectional bifilar helix antennas with wide axial ratio beamwidth. IET Microw. Antennas Propag. 2013, 7, 825-830. [CrossRef]

31. Park, W.B.; Park, Y.M.; Hwang, K.C. Low-profile ferrite loaded conical antenna. In Proceedings of the 2017 International Conference on Information and Communication Technology Convergence (ICTC), Jeju, Korea, 18-20 October 2017; pp. 564-566. [CrossRef]

32. Moon, H.; Lee, G.; Chen, C.; Volakis, J.L. An Extremely Low-Profile Ferrite-Loaded Wideband VHF Antenna Design. IEEE Antennas Wirel. Propag. Lett. 2012, 11, 322-325. [CrossRef]

33. Hyeonjin Lee, H.N.; Lim, Y. A design of printed square loop antenna for omni-directional radiation patterns. In Proceedings of the Radio and Wireless Conference, RAWCON '03, Boston, MA, USA, 13-13 August 2003; pp. 253-256. [CrossRef]

34. Electric Power Steering. Available online: http://www.sasreset.com/features/eps.htm (accessed on 25 May 2019).

(C) 2019 by the authors. Licensee MDPI, Basel, Switzerland. This article is an open access article distributed under the terms and conditions of the Creative Commons Attribution (CC BY) license (http://creativecommons.org/licenses/by/4.0/). 